\title{
Stage IVB Lip and Oral Cavity Cancer AJCC v8
}

National Cancer Institute

\section{Source}

National Cancer Institute. Stage IVB Lip and Oral Cavity Cancer A/CC v8. NCI Thesaurus. Code C132734.

Stage IVB includes: (Any T, N3, M0); (T 4b, Any N, M0). T4b: Tumor invades masticator space, pterygoid plates, or skull base and/or encases the internal carotid artery. N3: Metastasis in a lymph node larger than $6 \mathrm{~cm}$ in greatest dimension and ENE (-); or in a single ipsilateral lymph node larger than $3 \mathrm{~cm}$ in greatest dimension and $\mathrm{ENE}(+)$; or metastases in multiple ipsilateral, contralateral or bilateral lymph nodes any with ENE(+). M0: No distant metastasis. (AJCC 8th Ed.) 